\title{
Azithromycin as Macrolide of Choice in Patients with Preterm Premature Rupture of Membranes in Expectant Management: A Retrospective Study
}

Fernanda Oliveira Castilhos ( $\nabla$ fernandacastilhos@icloud.com )

Universidade Federal do Rio Grande do Sul (UFGRS)

Gabriel Cardozo Müller

UFRGS

Janete Vettorazzi

Universidade Federal do Rio Grande do Sul (UFGRS)

Daniela Vanessa Vettori

Universidade Federal do Rio Grande do Sul (UFGRS)

Maria Carolina Bittencourt Costa

UFRGS

Mariana Sbaraini

Universidade Federal do Rio Grande do Sul (UFGRS)

Mariana Ongaratto Scherer

Universidade Federal do Rio Grande do Sul (UFGRS)

Edimárlei Gonsales Valério

Universidade Federal do Rio Grande do Sul (UFGRS)

\section{Research Article}

Keywords: PPROM, latency period, latency, antibiotics, neonatal morbidity, azithromycin

Posted Date: December 3rd, 2021

DOI: https://doi.org/10.21203/rs.3.rs-1079921/v1

License: (a) This work is licensed under a Creative Commons Attribution 4.0 International License.

Read Full License 


\section{Abstract}

Background: Preterm premature rupture of amniotic membranes (PPROM) is responsible for about $30 \%$ of premature births, being associated with great neonatal morbidity and mortality. The use of antibiotics in expectant management seems to increase the latency period between PPROM and birth, as well as improving maternal and neonatal outcomes. However, short and long term benefits, and the ideal antibiotics regimen remains controversial.

Objective: This study seeks to demonstrate that the use of antibiotics, with azithromycin as macrolide of choice, in expectant management reduces the birth rate in the first 48 hours after PPROM, increasing the latency period between PPROM and birth.

Methods: Observational, retrospective cohort study in pregnant women with PPROM treated conservatively at the Hospital de Clínicas de Porto Alegre (HCPA), from January 2012 to December 2019. For the group that used antibiotics, the scheme was Azithromycin and Ampicillin for 48 hours, followed by Amoxicillin for 5 days, completing 7 days of treatment. Qualitative data was analyzed by Fisher exact test, and time to event analysis using Kaplan Meier estimator were used to evaluate latency to birth and Cox regression to estimate Hazard Rate.

Results: 145 participants, of which 107 did not use antibiotics (group 1) and 38 used antibiotics (group 2). The 48-hour birth rate was significantly lower in the antibiotics group (33.6\% in group 1 vs. $16 \%$ in group $2, p=0.04)$. The birth rate on patients presenting outcomes before 15 days presented a significant reduction (HR 0.6 [95\% ICl 0.39 - 0.92]), as well median time to birth as seen in Kaplan Meier estimator by log-rank test.

Conclusion: The use of this antibiotics regimen, with azithromicyn as macrolide of choice, reduced the birth rate in the first 48 hours, with potential clinical benefits due to the increase in the pharmacological window for corticosteroid action, among others, and increased median time to birth in first 15 days between PPROM and birth.

\section{Introduction}

Premature rupture of membranes (PROM) is when spontaneous rupture of fetal membranes occurs before labor. Preterm PROM (PPROM) is when this event happens before 37 weeks of gestation [1]. PPROM is an important cause of prematurity that occurs in $3 \%$ of all deliveries, and is associated with $1 / 3$ of all premature births [2,3]. On the other hand, prematurity is associated with $35 \%$ of neonatal deaths, being an important public health marker [4]. Lower gestational age and small birth weight are factors that are greatly associated with increased child mortality rate [5].

Management of patients with PPROM is still controversial, and there is no clear evidence on the ideal gestational age for termination of pregnancy. Nevertheless, expectant management between gestational ages (GAs) from 23-24 weeks to 33 weeks +6 days is currently recommended. Between GAs of 34 to 36 
weeks +6 days, ACOG [1] considers possible both immediate interruption and expectant management, but there is no consensus regarding this conduct among the main guidelines around the world. Immediate interruption is indicated for GAs above 37 weeks, when there are signs of maternal and/or fetal infection, or non-reassuring fetal status. The interruption is performed, in most cases, with induction of labor - if there is no contraindication to vaginal delivery [6].

The etiology of PPROM is multifactorial and often idiopathic. Infection can be associated both as a cause and as a consequence; therefore, in cases of expectant management, the use of antibiotics is widely investigated. The routine use of antibiotics seems to decrease maternal and fetal morbidity, in addition to increasing the latency period between rupture of membranes and childbirth [7]. The ideal combination of types of antibiotics and dosage is not yet well established and needs further studies to be elucidated [8]. The regimen recommended by ACOG is of erythromycin combined with ampicillin and amoxicillin [1]. However, other antibiotics regimens have been studied, showing similar outcomes [9-13].

The primary objective of this study is to evaluate the effectiveness of using Azithromycin and Ampicillin, followed by Amoxicillin, in reducing the birth rate in the first 48 hours after PPROM and increasing the latency time between PPROM and childbirth. Secondary objectives include evidence of a reduction in rates of chorioamnionitis, endometritis, perinatal morbimortality, among others.

\section{Materials And Methods}

Observational, retrospective cohort study in pregnant women with PPROM treated expectantly at Hospital de Clínicas de Porto Alegre (HCPA), Rio Grande do Sul - Brazil, from January 2012 to December 2019. Possible participants were identified with PPROM, with gestational ages between 23 weeks and 33 weeks and 6 days, through the review of medical records. Women who were already using antibiotics at the time of PPROM and/or had used any antibiotics in the last 7 days were excluded. Fetuses weighing less than the 10th percentile at admission and/or with malformations were excluded since they were potential confounding factors in the analysis of neonatal data. Pregnant women with cervical cerclage, uterine malformations and/or multiple pregnancies were also excluded.

Participants were divided into two groups: Group 1 did not receive any antibiotics and Group 2 received antibiotics. The regimen used in group 2 was oral Azithromycin 1 gram (g) single dose with intravenous Ampicillin $2 \mathrm{~g}$ as the loading dose and $1 \mathrm{~g}$ every 6 hours for 48 hours as the maintenance dose, followed by Amoxicillin $500 \mathrm{mg}$ every 8 hours for 5 days - completing 7 days of treatment. Latency time was defined as the time between PPROM and birth.

The diagnosis of amniorrhexis was made by specular examination, and gestational age was calculated using the earliest ultrasound performed. Participants were followed according to hospital protocol. Group B streptococcus (GBS) was investigated with vaginal and rectal swab, except for those already considered colonized, with urinary infection by GBS in this pregnancy or with a previous child who had GBS infection. Fetal wellbeing was assessed with fetal biophysical profile and serial cardiotocography. Ultrasound and tests such as blood count and urine analysis were also serially performed to assess fetal 
growth and to investigate infection, respectively. Data were collected for all participants in the period between January 2012 and December 2019.

The expected difference in birth rate in the first 48 hours after PPROM was of $32 \%$ between the groups, as described by Grable et al. We calculated that enrollment of 108 participants ( 27 in the first group and 81 in the second group) would provide a power of $90 \%$ to detect this difference, with an alpha of 0.05 . A great variability of this rate is found in the literature and is altered with the type of primary analyses that were made; however, we considered that this sample size was the minimum necessary to find a statistically significant difference considering a large effect size.

Analyses were performed using R Statistical Software (version 4.0.0, R Core Team. R: A language and environment for statistical computing. R Foundation for Statistical Computing, Vienna, Austria) and RStudio (version 1.1.4 RStudio Team. RStudio: Integrated Development for R. RStudio, Inc., Boston, MA). Numerical variables were evaluated for normality by histograms and by the Shapiro-Wilk test, and, presenting assimetry in these distributions, Mann-Whitney test was used. To dichotomous outcomes, Chi Square or Fisher exact test were used, and we also estimated Relative Risk and 95\% confidence intervals, using 5000 bootstrap simulations, as suggested by Mwangi et al. for unbalanced groups [14]. Time to event analysis was made using Kaplan Meier estimator, with comparison among groups made by logrank test.

Cox Proportional Hazards regression was used to to control for confounders, estimating models as proposed by Colosimo [15], checking proportional hazards assumption by visual inspection of Schoenfeld residuals and testing for trends towards time. In order to adjust for best fit model we used likelihood ratio test, Akaike and Bayesian Information Criteria (AIC and BIC). Differences were considered as statistically significant when the p-value was less than 0.05 .

\section{Results}

From January 2012 through December 2019, 433 potential participants were identified. Among these, 226 were excluded for not having criteria for PPROM or having gestational age less than 23 weeks or more than 34 weeks. The remaining 207 women had a diagnosis of PPROM and expectant management was indicated, but 62 had potential confusion factors for the outcomes and were excluded (Figure 1). A total of 145 pregnant women were included: 107 did not receive antibiotics (group 1) and 38 received antibiotics (group 2). Baseline characteristics of each group with information obtained on hospital admission (Table 1), showing similarity between the groups. 
Table 1

Obstetric and demographic data of the women included in the study.

\begin{tabular}{|c|c|c|}
\hline Demographic data at admission & $\begin{array}{l}\text { Group } 1 \\
\text { (No antibiotics) }\end{array}$ & $\begin{array}{l}\text { Group } 2 \\
\text { (With antibiotics) }\end{array}$ \\
\hline $\mathrm{n}$ & 107 & 38 \\
\hline Age, years & $26.0[21.0,33.0]$ & $25.0[20.0,33.8]$ \\
\hline \multicolumn{3}{|l|}{ Level of schooling } \\
\hline Complete primary school & $20(18.7)$ & $7(18.4)$ \\
\hline Incomplete elementary school & $40(37.4)$ & $11(28.9)$ \\
\hline Complete high school & $26(24.3)$ & $11(28.9)$ \\
\hline Incomplete high school & $9(8.4)$ & $4(10.5)$ \\
\hline Complete higher education & $3(2.8)$ & $1(2.6)$ \\
\hline Incomplete higher education & $9(8.4)$ & $4(10.5)$ \\
\hline \multicolumn{3}{|l|}{ Race } \\
\hline White & $71(66.4)$ & $26(68.4)$ \\
\hline Black & $20(18.7)$ & $9(23.7)$ \\
\hline Mixed & $16(15.0)$ & $3(7.9)$ \\
\hline Number of prenatal care visits & $4.0[3.0,6.0]$ & $5.0[3.0,6.0]$ \\
\hline \multicolumn{3}{|l|}{ Parity } \\
\hline Nulliparous & $37(34.6)$ & $12(31.6)$ \\
\hline \multicolumn{3}{|l|}{ Gestational age at PPROM } \\
\hline 23 weeks to 27 weeks +6 days & $21(19.6)$ & $10(26.3)$ \\
\hline 28 weeks to 30 weeks +6 days & $21(19.6)$ & $5(13.1)$ \\
\hline 31 weeks to 33 weeks +6 days & $65(60.7)$ & $23(60.5)$ \\
\hline \multicolumn{3}{|l|}{ Maternal comorbidities } \\
\hline Gestational diabetes & $6(4.3)$ & $9(15.8)$ \\
\hline Chronic hypertension & $4(2.8)$ & $1(1.8)$ \\
\hline Urinary tract infection during this pregnancy & $26(18.4)$ & $14(24.6)$ \\
\hline Previous premature labor & $18(12.8)$ & $3(5.3)$ \\
\hline Inhibition of premature labor during this pregnancy & $9(6.4)$ & $1(1.8)$ \\
\hline
\end{tabular}




\begin{tabular}{|lll|}
\hline Demographic data at admission & $\begin{array}{l}\text { Group 1 } \\
\text { (No antibiotics) }\end{array}$ & $\begin{array}{l}\text { Group 2 } \\
\text { (With antibiotics) }\end{array}$ \\
\hline Previous PPROM & $7(5.0)$ & $1(1.8)$ \\
\hline Smoking & $23(16.3)$ & $5(8.8)$ \\
\hline Asthma & $4(2.8)$ & $5(8.8)$ \\
\hline Psychiatric disorders & $7(5.0)$ & $1(1.8)$ \\
\hline First Trimester Bleeding & $6(4.3)$ & $0(0)$ \\
\hline Other maternal pathologies & $31(22.0)$ & $17(29.8)$ \\
\hline
\end{tabular}

\subsection{Latency Period}

The 48-hour birth rate was significantly lower in the antibiotics group $(\mathrm{n}=36$ [33.6\%] in group 1, vs. 6 [16\%] in group 2, RR 0.46 [95\% $\mathrm{Cl} 0.15-0.90], \mathrm{p}=0.04$ ), as shown in Table 2. The 7-day birth rate was also lower in the antibiotics group $(n=68$ [63.5\%] in group 1 vs. 18 [47\%] in group 2, RR 0.74 [95\% Cl $0.47-1.03]$, $p=0.09)$, though without statistical significance. 
Table 2

Obstetrics outcomes and maternofetal complications.

\begin{tabular}{|c|c|c|c|c|c|}
\hline & $\begin{array}{l}\text { Group } 1 \\
\text { (No antibiotics) }\end{array}$ & $\begin{array}{l}\text { Group } 2 \\
\text { (With antibiotics) }\end{array}$ & $\begin{array}{l}\mathrm{p}- \\
\text { value }\end{array}$ & RR & $95 \% \mathrm{Cl}$ \\
\hline$n$ & 107 & 38 & & & \\
\hline \multicolumn{6}{|l|}{ Outcomes } \\
\hline Birth in the first 48 hours & $36(33.6)$ & $6(15.8)$ & 0.04 & 0.46 & $\begin{array}{l}0.15- \\
0.90\end{array}$ \\
\hline Birth in the first 7 days & $68(63.6)$ & $18(47.4)$ & 0.09 & 0.74 & $\begin{array}{l}0.47 \\
-1.03\end{array}$ \\
\hline 1-minute APGAR < 7 & $32(29.9)$ & $8(21.1)$ & 0.39 & 0.70 & $\begin{array}{l}0.28- \\
1.28\end{array}$ \\
\hline 5-minutes APGAR $<7$ & $8(7.5)$ & $3(7.9)$ & 1.00 & 1.05 & $\begin{array}{l}0.0- \\
3.51\end{array}$ \\
\hline Birthweight. grams & $\begin{array}{l}1935 \text { [1503.8, } \\
2133.8]\end{array}$ & $\begin{array}{l}1900[1507.5, \\
2142.5]\end{array}$ & 0.82 & - & - \\
\hline Arterial cord pH & $7.31[7.26,7.35]$ & $7.29[7.25,7.34]$ & 0.62 & - & - \\
\hline Arterial cord base excess & $-3[-5.5,-1.8]$ & $-4.2[-6.1,-2.2]$ & 0.25 & - & - \\
\hline ICU lenght of stay, days & $20[11.0,43.0]$ & $21[14.0,33.25]$ & 0.82 & - & - \\
\hline \multicolumn{6}{|l|}{ Neonatal complications } \\
\hline Surfactant Use & $24(22.4)$ & $10(26.3)$ & 0.65 & 1.17 & $\begin{array}{l}0.56- \\
2.17\end{array}$ \\
\hline Neonatal ICU Hospitalization & $104(97.2)$ & $37(97.4)$ & 1.0 & 1.00 & $\begin{array}{l}0.92- \\
1.05\end{array}$ \\
\hline Ventilatory Support & $79(73.8)$ & $30(78.9)$ & 0.66 & 1.06 & $\begin{array}{l}0.85- \\
1.29\end{array}$ \\
\hline Necrotizing Enterocolitis & $10(9.3)$ & $2(5.3)$ & 0.73 & 0.56 & $\begin{array}{l}0.00- \\
1.87\end{array}$ \\
\hline Presumed Neonatal Sepsis & $82(76.6)$ & $27(71.1)$ & 0.52 & 0,93 & $\begin{array}{l}0.72- \\
1.15\end{array}$ \\
\hline Intracranial Hemorrhage & $11(10.3)$ & $6(15.8)$ & 0.38 & 1.54 & $\begin{array}{l}0.43- \\
3.75\end{array}$ \\
\hline Neonatal Pneumonia & $11(10.3)$ & $0(0.0)$ & 0.07 & 0.0 & $0.0-0.0$ \\
\hline Neonatal Death & $6(5.6)$ & $3(7.9)$ & 0.69 & 1.40 & $\begin{array}{l}0.0- \\
5.63\end{array}$ \\
\hline Meningitis & $6(5.6)$ & $0(0.0)$ & 0.34 & 0.0 & $0.0-00$ \\
\hline
\end{tabular}




\begin{tabular}{|llllll|}
\hline & $\begin{array}{l}\text { Group 1 } \\
\text { (No antibiotics) }\end{array}$ & $\begin{array}{l}\text { Group 2 } \\
\text { (With antibiotics) }\end{array}$ & $\begin{array}{l}\text { p- } \\
\text { value }\end{array}$ & RR & 95\% Cl \\
\hline Cardiorrespiratory Arrest & $2(1.9)$ & $2(5.3)$ & 0.28 & 2.82 & $0.0-0.0$ \\
\hline Septic Shock & $5(4.7)$ & $1(2.6)$ & 1.00 & 0.56 & $0.00-$ \\
\hline Other Complications & $15(14.0)$ & $5(13.2)$ & 1 & 0.93 & $0.21-$ \\
\hline Maternal complications & & & & & 2.19 \\
\hline Clinical Chorioamnionitis & $28(26.2)$ & $9(23.7)$ & 0.83 & 0.90 & $0.41-$ \\
\hline $\begin{array}{l}\text { Endometritis } \\
\text { Maternal Sepsis Sepsis }\end{array}$ & $1(0.9)$ & $0(0.0)$ & 1.0 & 0.0 & $0.0-0.0$ \\
\hline $\begin{array}{l}\text { Aditional Hypotonia } \\
\text { Management }\end{array}$ & $4(3.7)$ & $0(0.0)$ & 1 & 0.0 & $0.0-0.0$ \\
\hline
\end{tabular}

We also performed time-to-event analysis using Cox regression, fitting several multivariate models. Even so, the best fit was univariate with antibiotics treatment. Also, in order to do not violate proportional hazards assumption, we stratified our population in those with event before and after 15 days.

In population with event before 15 days, we have observed a significant reduction events rate HR 0.6 [95\% ICI 0.39 - 0.92] when comparing antibiotics treatment group with non-treated group, as estimated by Cox PH. Also, by Kaplan-Meier estimator (Fig. 2), we also detected higher median time in $\mathrm{G} 2$ ( 94 hours [95\% Cl 72-216]) in comparison with G1 (70 hours [95\% Cl 45-96]), as detected by log-rank test (chi square $=5.3,1$ d.f., $p=0.02)$ (Fig. 2a).

Even so, in strata of birth after 15 days, we did not observed a significant difference both in Cox (HR 2.2 [95\%IC 0.76 - 6.39], p=0.14) model and Kaplan Meier curve (546 hours [95\%IC 450-564] in G1 e 534 hours [95\%IC 432-Inf] no G2, Chi-square=0.4, 1 d.f., $p=0.50$, Log-rank test) (Fig. 2b). However, low number of events could explain high amplitude of variances, limiting robustness of these estimates.

\subsection{Obstetrics Outcomes And Maternofetal Complications}

No significant difference between groups was found for other outcomes described in Table 2, such as the need for admission to a neonatal ICU and/or days of hospitalization, APGAR in 1 and 5 minutes, $\mathrm{pH}$ and excess base in the newborn's blood gas analysis and birth weight. Caesarean indications were similar between groups. 
We also described neonatal complications (Table 2), finding no significant difference was found between the groups. Six (5.6\%) newborns with meningitis were identified in group 1, and none in the antibiotics group. Neonatal pneumonia was present in 11 newborns in group $1(10.28 \%, p=0.19)$ and in 1 in group 2 $(2.56 \%, p=0.18)$. There was also no difference in the outcome of necrotizing enterocolitis ( 10 newborns [9.35\%] in group 1 vs. 2 [5.13\%] in group 2, p=0.51). As for maternal complications, endometritis was found in six postpartum women in group 1 and none in the antibiotics group, but without statistical significance $(p=0.19)$. There was also no significant difference between groups regarding maternal sepsis or the need for management of uterine atony. Anatomopathological examination of 123 placentas was performed, showing chorioamnionitis in 76 placentas, with no difference between groups.

\section{Discussion}

Our cohort study demonstrates an increased latency time between PPROM and birth in the group that received antibiotics, reducing the 48-hour birth rate and increased median latency time in 15 days strata, as well rate of events on this specified period. Some studies show similar results, with increased latency time with the use of antibiotics [16-19]. However, to our knowledge, this is the first study using the antibiotics regimen of azithromycin and ampicillin, followed by amoxicillin, compared to not using antibiotics.

The main international guidelines recommend the combination of a beta-lactam antibiotic (penicillin, ampicillin and/or amoxicillin) associated with a macrolide (erythromycin) [1, 20, 21]. Nevertheless, a recent meta-analysis concluded that data in this subject are still insufficient to determine the best antibiotic regimen [22]. With the exception of amoxicillin + clavulanate, which increased the risk of necrotizing enterocolitis, no antibiotic regimen was found to be superior to the other [8].

The combination that was administered in our study, using azithromycin as the macrolide of choice, has been tested more recently and appears to be a good option, due to having a lower cost, easier administration (single oral dose), easier access and availability in developing countries, and reduced side effects when compared to erythromycin, with no difference in latency time between groups $[10,11,13$, 23]. Noteworthy, erythromycin is not available in unified health system (SUS) funded hospitals.

In this context, a multicenter retrospective cohort compared different doses of azithromycin (single dose, 5 days or 7 days) versus erythromycin, showing no difference in latency time between the 4 groups. The latency time was on average 5 days, while in our study the average time was higher, of 8 days [23].

Compared to a study conducted by Kenyon et al [17], we found similar 48-hour birth rates in the group without antibiotics (35.6\% vs. 33.6\%, respectively); however, our study had a lower percentage of births in the first 48 hours in the group with antibiotics $(33.0 \%$ vs. $16.0 \%)$. The same trend was found when comparing birth rates in 7 days, in the group without antibiotics $(60.5 \% \mathrm{vs} .63 .5 \%)$ and in the group with antibiotics (57.7\% vs. $47.0 \%$ ) [17]. On time to event analysis, this antibiotic scheme has increased latency, limited to 15 days strata, that could be explained to antibiotics phamarcokinetics [24] . 
A 2013 Cochrane review with 22 randomized clinical trials showed that the use of antibiotics in PPROM reduced the rates of chorioamnionitis, abnormal brain ultrasound before hospital discharge, neonatal infection, and surfactant and oxygen use in the newborn[8]. Among the many benefits of reducing the 48hour birth rate after PPROM, which was demonstrated in this study, is the increase of the therapeutic window for administration of antenatal corticosteroids. Its use after PPROM is associated with a reduction in neonatal mortality, respiratory dysfunction, intraventricular hemorrhage and necrotizing enterocolitis [7, 25, 26].

Our study demonstrated lower rates of endometritis, pneumonia and neonatal meningitis in the group that used antibiotics, though without statistical significance. The fact that we did not find any difference in such maternal and neonatal outcomes can be explained by our small sample size, which is a limitation of the study. Due to the impossibility of conducting a prospective study with this design for ethical reasons, we suggest further retrospective studies with a larger sample size enrolled, in order to better evaluate maternal and neonatal outcomes. In addition, we also highlight the need to conduct randomized clinical trials comparing different antibiotic regimens, considering that there is still a gap regarding the ideal antibiotic regimen (drugs and doses) to be used in this group of patients. Even though, observational studies with proper confounder control may be a source of causal inference, which enhances validity of our results $[27,28]$.

\section{Conclusion}

In women with PPROM, the use of the antibiotics regimen consisting of oral Azithromycin $1 \mathrm{~g}$ single dose and intravenous Ampicillin $2 \mathrm{~g}$ as the loading dose and $1 \mathrm{~g}$ every 6 hours for 48 hours as maintenance, followed by Amoxicillin $500 \mathrm{mg}$ every 8 hours for 5 days (total of 7 days of treatment), significantly reduced the 48-hour birth rate and time to birth in 15 days strata, compared to not using antibiotics. Confirming previous findings, it also increased the latency time between PPROM and birth, with an important clinical benefit by increasing the pharmacological action window for corticotherapy.

\section{Declarations}

\section{Ethics approval statement}

The study was approved by the Ethics in Research Committee at HCPA and at Plataforma Brasil (CAAE: 16917619.3.0000.5327), all participating members signed data use agreement. The use of informed consent was waived, given that the data were extracted from medical records and anonymized for analyses. This manuscript was written following STrengthening the Reporting of OBservational studies in Epidemiology (STROBE) [1] guidelines.

\section{Authors consent}

All authors contributed to material preparation and data collection. Study conception and design and data analysis were performed by Castilhos, F.O., Müller, G.C., Valério, E.G.. Also helped on the data 
collection and figures preparation Vettorazzi, J, Vettori, D.V., Costa, M.C.B., Mariana Sbaraini, M., Scherer, M.O.. The first draft of the manuscript was written by Fernanda Oliveira Castilhos and all authors commented on previous versions of the manuscript.

\section{Data availability}

Data will be made available if requested to corresponding author.

\section{Funding Details}

No author has relevant financial or non-financial sponsorship to declare.

\section{Disclosure of Interest}

The authors declare no conflict of interest. All Authors listed on the title page have contributed significantly to the work, have read the manuscript, attest to the validity and legitimacy of the data and its interpretation, and agree to its submission to this journal.

\section{Consent to publication}

All authors read and approved the final version of this manuscript and consented to its publication.

\section{Ackowledgements}

We declare no acknowledgements in this study. This project did not receive specific funding. The authors used their own resources to cover the costs of the study

\section{References}

1. ACOG Practice Bulletins. Clinical Management Guidelines for Obstetrician - Gynecologists. Obstet Gynecol. 2020;133:168-86.

2. Waters TP, Mercer B. Preterm PROM: Prediction, Prevention, Principles. 2011;54:307-12.

3. Taylor HG, Klein N, Minich NM, Hack M. Long-term family outcomes for children with very low birth weights. Arch Pediatr Adolesc Med. 2001;155:155-61.

4. Blencowe H, Cousens S, Oestergaard MZ, Chou D, Moller AB, Narwal R, et al. National, regional, and worldwide estimates of preterm birth rates in the year 2010 with time trends since 1990 for selected countries: A systematic analysis and implications. Lancet. 2012;379:2162-72.

5. Matthews TJ, MacDorman MF. Infant mortality statistics from the 1999 period linked birth/infant death data set. Natl Vital Stat Rep. 2002;50.

6. Hannah ME, Ohlsson A, Farine D, Hewson SA, Hodnett ED, Myhr TL, et al. Induction of Labor Compared With Expectant Management for Prelabor Rupture of the Membranes at Term. Obstet Gynecol Surv. 1996;51:522-3. 
7. Mercer BM. Antibiotic Therapy for Reduction of Infant Morbidity After Preterm Premature Rupture of the Membranes. Jama. 1997;278:989.

8. Kenyon S, Boulvain M, Neilson JP. Antibiotics for preterm rupture of membranes. Cochrane Database Syst Rev. 2013;2013.

9. Pierson R, Gordon S, Haas D. A Retrospective Comparison of Antibiotic Regimens for Preterm Premature Rupture of Membranes. Obstet Gynecol. 2016;127:e39-51.

10. Ehsanipoor RM, Chung JH, Clock CA, McNulty JA, Wing DA. A retrospective review of ampicillinsulbactam and amoxicillin + clavulanate vs cefazolin/cephalexin and erythromycin in the setting of preterm premature rupture of membranes: maternal and neonatal outcomes. Am J Obstet Gynecol. 2008;198:54-6.

11. Finneran MM, Appiagyei A, Templin M, Mertz H. Comparison of Azithromycin versus Erythromycin for Prolongation of Latency in Pregnancies Complicated by Preterm Premature Rupture of Membranes. Am J Perinatol. 2017;34:1102-7.

12. Lee J, Romero R, Kim S, Chaemsaithong P, Yoon B. A New Antibiotic Regimen Treats and Prevents Intra-Amniotic Infection/Inflammation in Patients with Preterm PROM. J Matern Fetal Neonatal Med. 2016;29:2727-2737.

13. Finneran MM, Smith DD, Buhimschi CS. Cost Analysis of Azithromycin versus Erythromycin in Pregnancies Complicated by Preterm Premature Rupture of Membranes. Am J Perinatol. 2019;36:105-9.

14. Mwangi OW, Islam A, Luke O. Bootstrap Confidence Intervals for Proportions of Unequal Sized Groups Adjusted for Overdispersion. Open J Stat. 2015;05:502-10.

15. Colosimo E., Giolo S. Análise de Sobrevivência Aplicada. 2010;:108-48.

16. Mercer BM, Moretti ML, Prevost RR, Sibai BM. Erythromycin therapy in preterm premature rupture of the membranes: A prospective, randomized trial of 220 patients. Am J Obstet Gynecol. 1992;166:794-802.

17. Kenyon SL, Taylor DJ, Collaborative O. Broad-spectrum antibiotics for preterm, prelabour rupture of fetal membranes: the ORACLE I randomised trial. 2001;357:979-88.

18. Dirnagl U, Klehmet J, Braun JS, Harms H, Meisel C, Ziemssen T, et al. Stroke-Induced Immunodepression. Stroke. 2007;38:770-3. doi:10.1161/01.STR.0000251441.89665.bc.

19. Johnston MM, Sanchez-Ramos L, Vaughn AJ, Todd MW, Benrubi GI. Antibiotic therapy in preterm premature rupture of membranes: A randomized, prospective, double-blind trial. Am J Obstet Gynecol. 1990;163:743-7.

20. Tchirikov M, Schlabritz-Loutsevitch N, Maher J, Buchmann J, Naberezhnev Y, Winarno AS, et al. Midtrimester preterm premature rupture of membranes (PPROM): Etiology, diagnosis, classification, international recommendations of treatment options and outcome. J Perinat Med. 2018;46:465-88.

21. Yudin MH, van Schalkwyk J, Eyk N Van, Boucher M, Castillo E, Cormier B, et al. Antibiotic Therapy in Preterm Premature Rupture of the Membranes. J Obstet Gynaecol Canada. 2009;31:863-7. 
22. Chatzakis C, Papatheodorou S, Sarafidis K, Dinas K, Makrydimas G, Sotiriadis A. Effect on perinatal outcome of prophylactic antibiotics in preterm prelabor rupture of membranes: network metaanalysis of randomized controlled trials. Ultrasound Obstet Gynecol. 2020;55:20-31.

23. Navathe R, Schoen CN, Heidari P, Bachilova S, Ward A, Tepper J, et al. Azithromycin vs erythromycin for the management of preterm premature rupture of membranes. Am J Obstet Gynecol. 2019;221:144.e1-144.e8.

24. Ramsey PS, Vaules MB, Vasdev GM, Andrews WW, Ramin KD. Maternal and transplacental pharmacokinetics of azithromycin. Am J Obstet Gynecol. 2003;188:714-8.

25. Roberts D, Brown J, Medley N, Dalziel SR. Antenatal corticosteroids for accelerating fetal lung maturation for women at risk of preterm birth. Cochrane Database Syst Rev. 2017;2017.

26. Vidaeff AC, Ramin SM. Antenatal corticosteroids after preterm premature rupture of membranes. Clin Obstet Gynecol. 2011;54:337-43.

27. Hernan MA. Methods of Public Health Research - Strengthening Causal Inference from Observational Data. 2021;:1345-8.

28. Greenland S, Pearl J, Robins JM. Causal diagrams for epidemiologic research. Epidemiology. 1999;10:37-48.

29. von Elm E, Altman DG, Egger M, Pocock SJ, Gøtzsche PC, Vandenbroucke JP. The Strengthening the Reporting of Observational Studies in Epidemiology (STROBE) statement: guidelines for reporting observational studies. Lancet. 2007;370:1453-7.

\section{Figures}




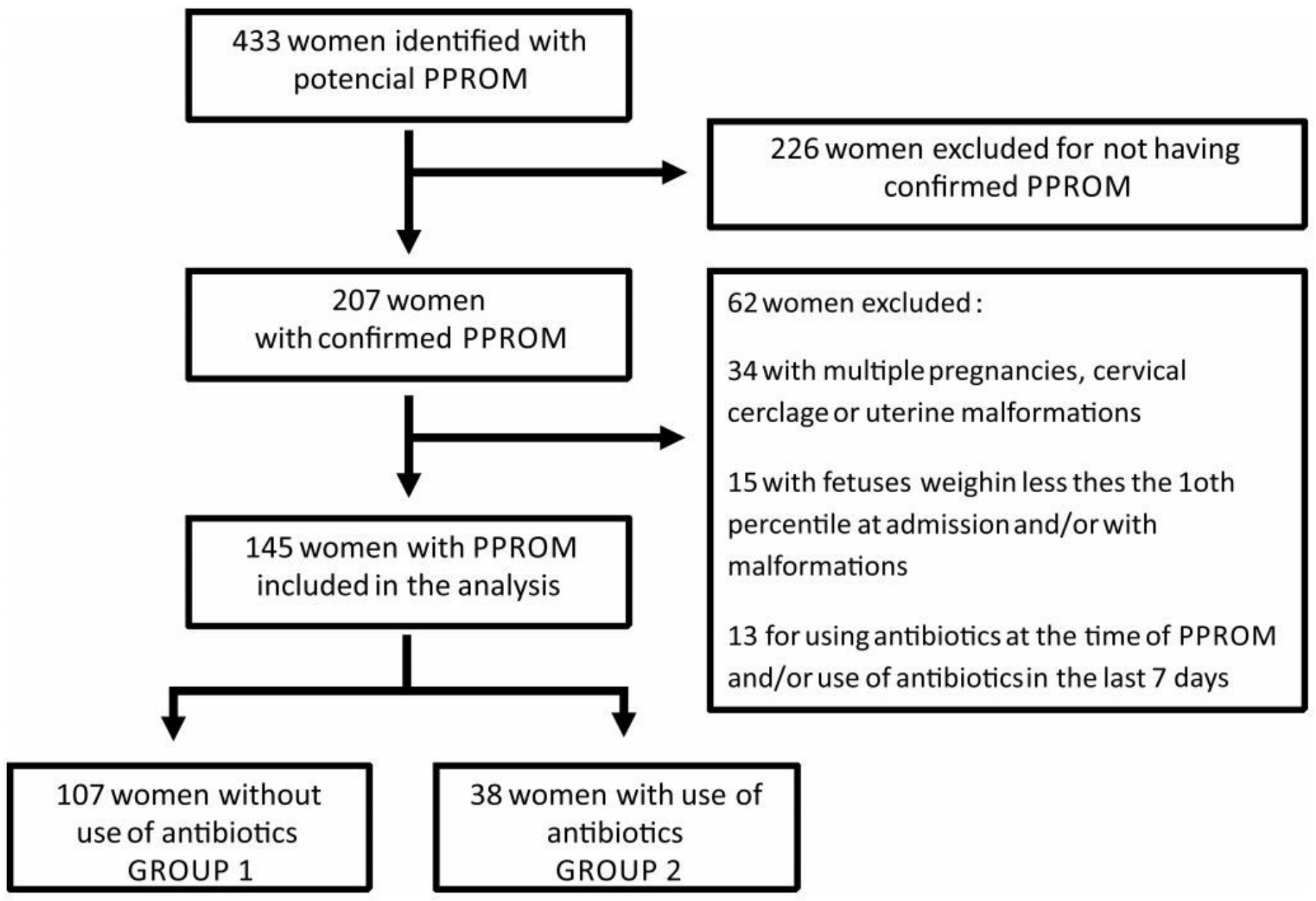

Figure 1

Flowchart of patients selection. 
a

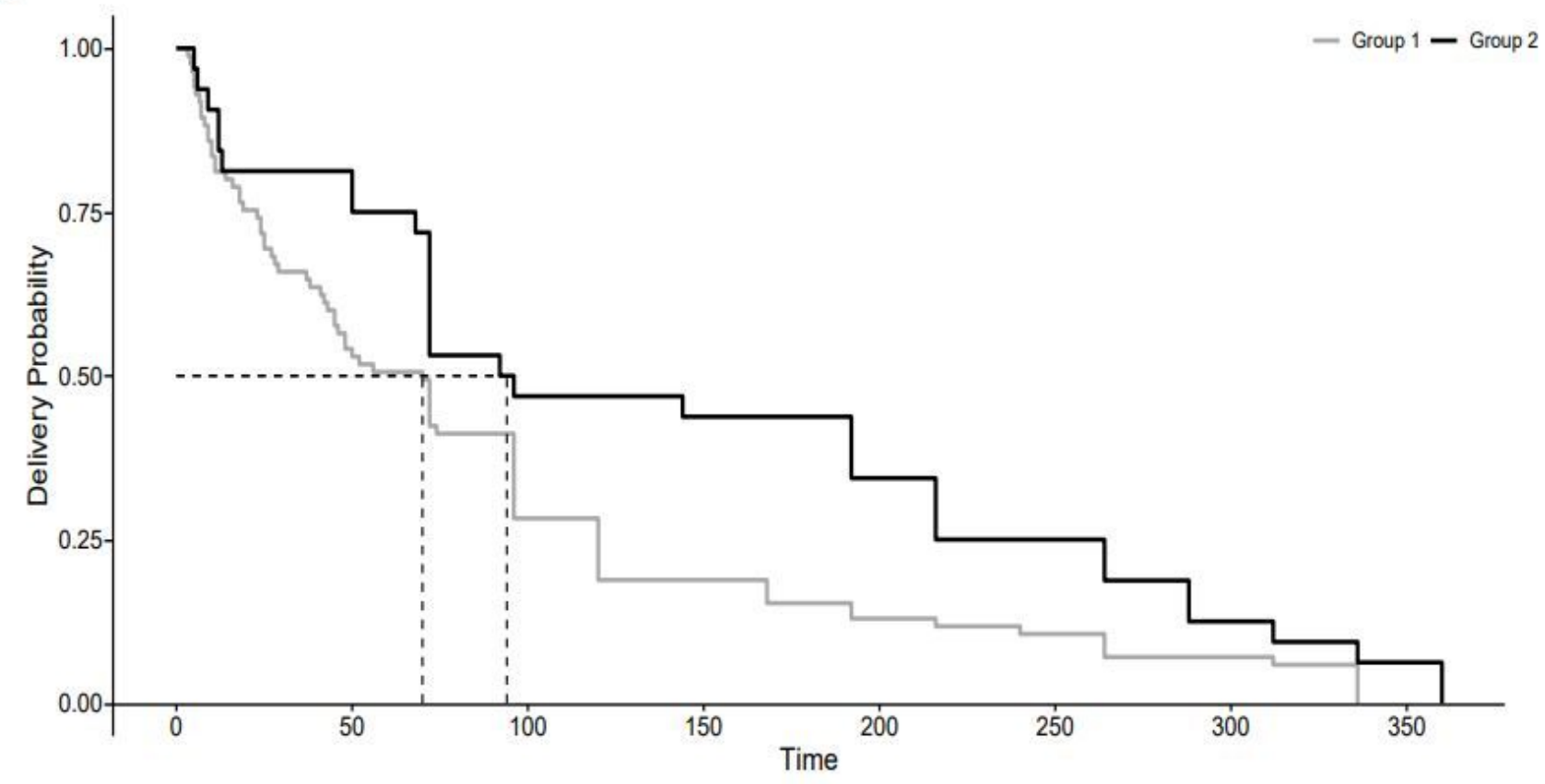

b

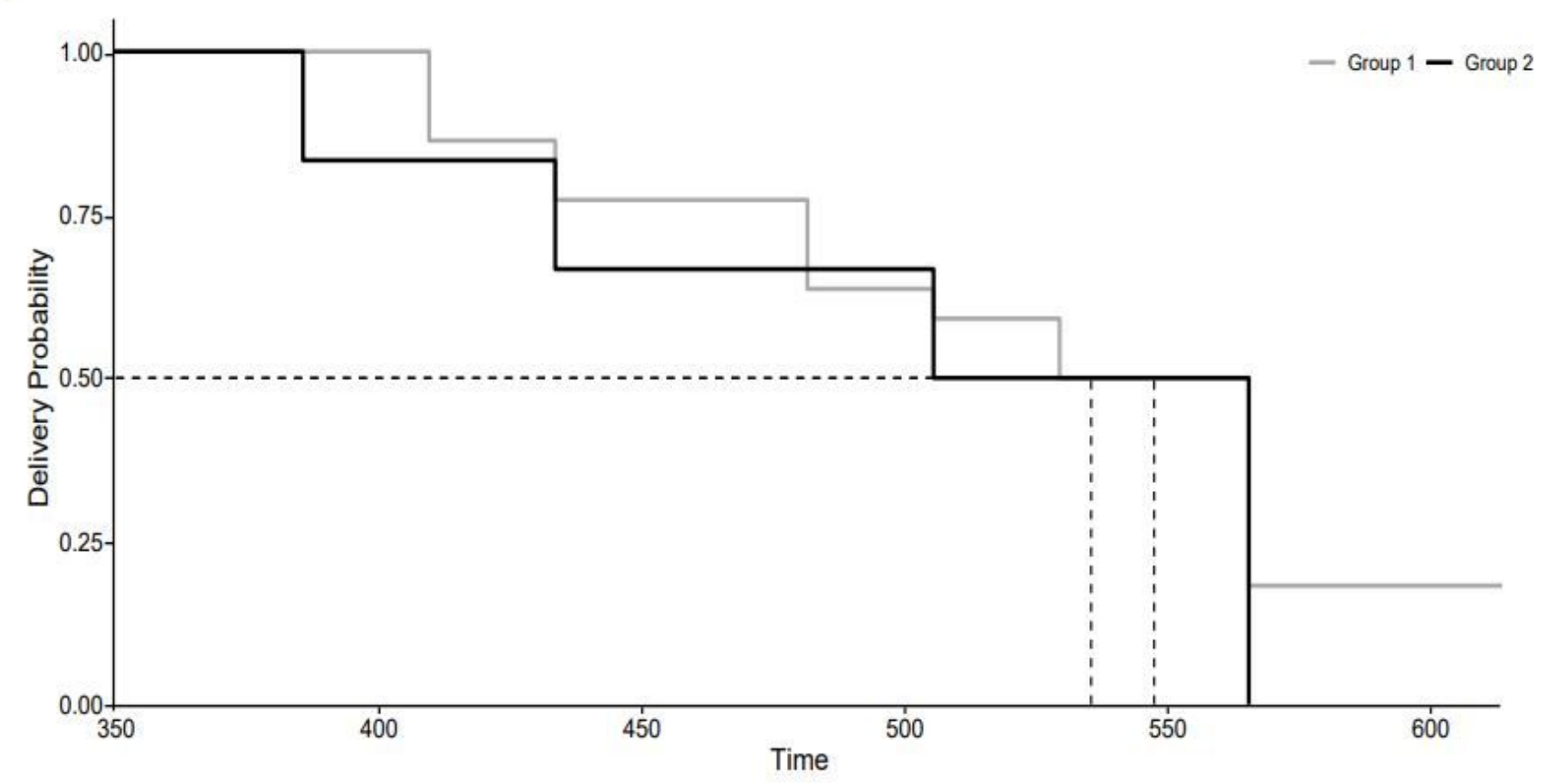

Figure 2

Kaplan Meier survival curves of latency period duration by antibiotic treatment. (a) up to 15 days after PPROM and (b) after 15 days post PPROM. In the Kaplan Meier survival curves, G1 is represented in black and $\mathrm{G} 2$ in grey, $\mathrm{x}$-axis representing time in hours and $y$-axis probability of birth event. Log-Rank test, $p=0.01$. 